San Jose State University

SJSU ScholarWorks

Master's Projects

Master's Theses and Graduate Research

$5-1-2006$

\title{
The Relationship Between Parental Physical Activity Levels and Their Child's Body Mass Index
}

Juracia Carbajal

San Jose State University

Follow this and additional works at: https://scholarworks.sjsu.edu/etd_projects

Part of the Other Nursing Commons

\section{Recommended Citation}

Carbajal, Juracia, "The Relationship Between Parental Physical Activity Levels and Their Child's Body Mass Index" (2006). Master's Projects. 750.

DOI: https://doi.org/10.31979/etd.agk8-ycwp

https://scholarworks.sjsu.edu/etd_projects/750

This Master's Project is brought to you for free and open access by the Master's Theses and Graduate Research at SJSU ScholarWorks. It has been accepted for inclusion in Master's Projects by an authorized administrator of SJSU ScholarWorks. For more information, please contact scholarworks@sjsu.edu. 


\section{SAN JOSE STATE UNIVERSITY \\ SCHOOL OF NURSING}

\section{MASTER'S PROGRAM PROJECT OPTION (PLAN B)}

\section{PROJECT SIGNATURE FORM}

STUDENT NAME

$$
\text { Juracia Carbajal }
$$

SEMESTER ENROLLED

Spring 2006

TITLE OF PROJECT

The Relationship Between

Parental Physical Activity Levels and Their Child's Body Mass Index

\section{NAME OF JOURNAL}

\section{The Journal of School Nursing}

The project and the manuscript have been successfully completed and meet the standards of the School of Nursing University. The project demonstrates the application of professional knowledge, clinical expertise, and scholarly thinking. An abstract of the project and two copies of the manuscript are attached.
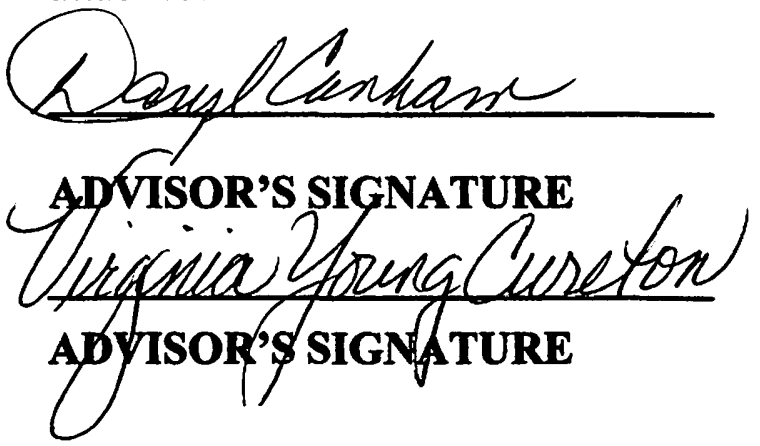

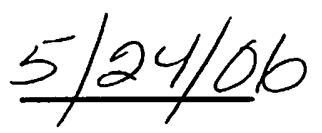

DATE

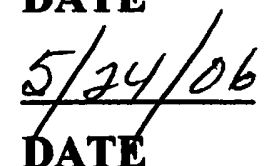

Please submit the form to the Graduate Coordinator. Attach abstract, two copies of the manuscript, and the documentation of submission to the journal (i.e., postal receipt). 
THE RELATIONSHIP BETWEEN PARENTAL PHYSICAL ACTIVITY LEVELS AND THEIR CHILD'S BODY MASS INDEX

\author{
Author Information: \\ Maria Luzelle Advincula, RN, BSN, MS (c) \\ is currently a staff nurse at Lucile Packard Children's Hospital in Palo Alto, CA. \\ Juracia Vieira Carbajal, RN, BSN, MS \\ is currently a school nurse for the Gilroy Unified School District in Gilroy, CA. \\ Daryl Canham, RN, EdD, BC. \\ Associate Professor of Nursing, San Jose State University, San Jose, CA, \\ was the first reader on this project. \\ Virginia Young-Cureton, RN, DPH. \\ Professor of Nursing, San Jose State University, San Jose, CA, \\ was the second reader on this project. \\ The first two authors did this study jointly as a master's degree project at \\ San Jose State University, San Jose, CA.
}

Contact Information:

Juracia Carbajal 


\title{
THE RELATIONSHIP BETWEEN PARENTAL PHYSICAL ACTIVITY LEVELS AND THEIR CHILD'S BODY MASS INDEX
}

\begin{abstract}
This study compared the relationships between parental physical activity levels and their child's body mass index (BMI) using a convenience sample of volunteer parents at a school-based health clinic. Anonymously, parents completed a sevenquestion survey utilizing the International Physical Activity Questionnaire (IPAQ). The data analysis indicated that parental physical activity did not have a significant influence on a child's BMI. Forty-two percent of the children were overweight or at risk for overweight, demonstrating the need for increased physical activity and improved nutritional guidance. The school nurse has a significant role in providing education about health, nutrition, and obesity prevention strategies for students, staff members, and families.
\end{abstract}

KEY WORDS: body mass index, children, obesity, overweight, physical activity 


\section{INTRODUCTION}

The incidence of being overweight or obese is a significant health problem for over 30\% of the United States' population. According to the Centers for Disease Control and Prevention $(C D C)$, the number of our country's youth who are overweight has tripled since 1980 (2005). Results from the 1999-2002 National Health and Nutrition examination Survey (NHANES) indicate $16 \%$ of children and adolescents are obese or overweight which is a significant increase from 4 to $5 \%$ in the 1963-1970 statistics (National Center for Health Statistics, 2005).

More than $50 \%$ of adults and more than a third of young people in the U.S. do not get enough physical activity. Physical activity has widely been considered an important component for a healthy lifestyle and may help to decrease the health risks associated with obesity. There are proven health benefits of physical activity for young people such as building healthy bones and muscles, increasing self-esteem, controlling weight, reducing incidences of diabetes, reducing high blood pressure, and decreasing anxiety and stress. Youth should be encouraged to participate in moderate physical activity levels of at least 60 minutes a day as recommended by the Surgeon General (U.S. Department of Health and Human Services, 2005).

In Northern California, approximately one in seven children ages $0-4$ years, and one in five ages 5-19 years were overweight in 2003. Hispanic children at $26 \%$ were the highest percentage of overweight children ages 5-19 years old, followed closely by Caucasian children at 24\% (Santa Clara County Public Health Department, 2005). At $31 \%$ of the student population, a small suburban town has the highest percentage of overweight children in the county (California Center for Public Health Advocacy, 2005). 
The purpose of this study was to examine any relationships that could be identified between a parent's physical activity level and their child's BMI. The researchers based this study on the assumption that parents who are regularly physically active have an impact on their children being regularly involved in more physical activities resulting in lower BMI's.

\section{REVIEW OF THE LITERATURE}

Welk, Wood, and Morss (2003) found that active parents were more likely to be involved, encouraging, and supportive of their child's physical activity. The researchers also found that parental influence played a significant role in a child's physical activity behaviors. The findings reveal that parental influence is important in the physical activity levels of their children. Investigating the activity levels of parents may be important to help determine if children are being influenced to be physically active.

Using data obtained by the Santa Clara County Public Health Department (2003), from the California Healthy Kids Survey, key areas of concern were identified for the targeted Hispanic research population, including overweight and obesity. Specific concerns addressed included nutrition education in the school setting and for the family, along with increasing physical activity to prevent or decrease overweight and obesity.

Among the students surveyed, $32 \%$ perceived themselves as being overweight. This report presents a comparison of children's health and development levels as compared to the U.S. Department of Health and Human Services' Healthy People 2010 Objectives (2000), the youth of California, and the nation's youth. 
The U.S. Department of Health and Human Services' Healthy People 2010 Objectives (2000) identify 10 major public health issues that are leading health indicators. Physical activity, obesity, and overweight are among the 10 leading health indicators. The target number of adolescents who participate in regular physical activity is $85 \%$ by the year 2010 . Only $65 \%$ of adolescents engaged in vigorous physical activity that promoted cardio-respiratory fitness three or more days per week for at least 20 minutes in the years 1990-1999 (Leading Health Indicators, 2000). The Healthy People 2010 goal for obesity and overweight children and adolescents is to decrease the proportion to $5 \%$. From the years $1988-1990,11 \%$ of children and adolescents were overweight or obese (Leading Health Indicators, 2000). These rates show that prevention and intervention must take place in order to achieve the goals that have been set.

An Australian study by Hesketh, Waters, Green, Salmon, and Williams (2005) correlated the views of children and parents regarding barriers to healthy eating, physical activity, and child obesity prevention programs. Using Parent focus groups, they identified contradictions in health messages children receive from their parents.

Parents reported a desire to learn how to encourage their children to eat healthy and be more physically active. Parents identified the role of the family as the primary source for learning about healthy lifestyles. The role of the school was considered secondary to that of the family (Hesketh et al., 2005).

An article by Gance-Cleveland and Bushmiaer (2005) described how schools in Arkansas successfully implemented a statewide mandated BMI measurement in collaboration between school health personnel, public health officials, state legislators, 
and school administrators. School nurses were able to obtain data including assessing BMl's on more than 400,000 students in the public school system.

With the data, schools gained funds to provide health education for students and to provide parents with health reports and education about the health effects of BMI-forage, nutrition, and physical activity. The data collected in Arkansas showed more ethnic minority youth classified as overweight or at risk for overweight, with $46 \%$ of Hispanic youth compared to $37 \%$ of Caucasian youth.

Pangrazi, Beighle, Vehige, and Vack (2003) conducted a school-based intervention program to promote physical activity in 4th grade classes and the researchers found that the students who participated in the program had lower body mass indices and were more involved in physical activity than those students who did not participate in the program. The researchers also found that the students who were not encouraged to participate in more physical activity through the program had lower activity levels and higher body mass indices.

Danielzik, Langnase, Mast, Spethmann, and Muller (2002) state that there are previous proposals that childhood obesity may result from genetic factors or familial risk and may not be significantly affected by environment. These researchers previously found a positive relation between parental weight and children's body mass index that confirms genetic influence, and found that being overweight is a risk factor for children if at least one parent is overweight.

Ethnic, racial "minority," and lower socioeconomic groups are greatly affected by obesity with a high prevalence in overweight among Hispanic children. Overweight in childhood is related to family perceptions and understanding regarding obesity and 
health, parent and family lifestyle patterns, and family and individual nutritional status (Rich et al., 2005). The parent's perceptions about weight and nutrition help provide more effective prevention strategies and interventions could be more culturally sensitive. The prevalence of overweight children in the Hispanic population indicates this group is at high risk of co-morbidities related to overweight and obesity. The CDC (2005) suggests that planning for weight control interventions should include a combination of both nutrition and physical activity components. Parents and students also need to be educated and involved in the school and available extracurricular activities providing physical activity and nutrition education.

School settings can promote or utilize existing programs, resources, and tools to develop student and community knowledge, attitudes, and necessary skills for healthy lifestyles. Parents and families can learn a great deal from educational resources to achieve a knowledge base to enhance the family health status. Families can learn that keeping fit and physically active together can help the entire family reduce risks for obesity and obesity related diseases (CDC, 2005).

Fisher, Lange, Young-Cureton \& Canham (2005) examined the relationship between body satisfaction and BMI among minority children. The study found that Hispanic children were at greater risk for overweight, but the majority of those students perceived themselves as having an ideal body weight. Only $2 \%$ of the students surveyed identified themselves as being overweight. Education about a healthy body image is also an important lesson component school nurses need to address in health education for students and families (Fisher et al., 2005). 


\section{THEORETICAL FRAMEWORK}

This study was based on the assumption that if a parent has high levels of physical activities then their child will also have high levels of physical activities; therefore the child will have less tendency of being overweight and have normal BMI levels. Albert Bandura's Social Learning Theory, also known as Social Cognitive Theory, emphasizes the influence of observing and modeling the behaviors, attitudes, and emotional reactions of others (Social Learning Theory, 2005). This coincides with how children model parental influences, behaviors, and attitudes about physical activity.

One of the principles of Bandura's Social Learning Theory explains that individuals are more likely to adopt a modeled behavior if the model is similar to the observer and has admired status (Social Learning Theory, 2005). This principle is true for most parent and child relationships. Children observe the actions of their parents, parents are their role models, and therefore, their children will adopt their behaviors as being valuable and acceptable. Children naturally look to their parents and may perceive what their parents do as the ideal. In a family setting where parents are physically active and value and maintain a healthy lifestyle, their children should grow mature while observing these behaviors and in turn will model and value these healthy behaviors and maintain healthy and active lifestyles throughout their future lives.

Another principle of this theory is that individuals are more likely to adopt a modeled behavior if it results in outcomes they value (Social Learning Theory, 2005). Educating children on the importance of being physically active should be done even at an early age so they learn to value physical activity. If parents are educated on the 
importance of physical activity and value it, their beliefs may reflect on the physical activity levels of their children as well.

\section{METHODOLOGY}

The design for this project was a correlation study using quantitative data from a convenience sample of parents recruited from families of clients served at a school-based neighborhood community clinic in a suburban area of Northern California. This schoolbased community clinic provides basic health care services to children between the ages of newborn to 18 years of age that live in the attendance boundary area of one large school district. The clinic is open Monday through Friday, 8:30 am until 5:00 pm, and closed for lunch one hour a day.

The clinic's mission is to provide preventative focused and accessible health care to low-income residents with limited access to health care. This clinic also provides services to help families apply for government issued health insurance. There are Spanish-speaking personnel available for translation. The clinic does not refuse service to anyone. Approximately 15-20 children are provided with health care services at the clinic each day.

On-site services at the neighborhood community clinic include physical examinations, immunizations, diagnostic testing, dental screenings and referrals, mental health care and referrals, and referrals to specialized health care providers. The clinic is staffed with bilingual nurse practitioners, medical assistants, receptionists, and volunteer physicians from the local medical community as consultants (School Health Clinics of Santa Clara County, 2005). Following IRB approval and approval from the clinic 
administrators and the school district, data were collected over 12 days, 6 hours per day, over a 3-week period in March of 2006.

Two nurse practitioners, one medical assistant and one receptionist at the schoolbased clinic assisted with the recruitment of participants. Flyers were also posted in the clinic and the schools. The flyers, available in both English and Spanish, indicated the purpose of the study and information for the parents. The research team approached prospective parent participants, to determine their interest in completing a short sevenitem questionnaire, and provide the survey for parents to complete. The research team was available to respond to questions.

A parent's signed consent was required prior to obtaining any data. Spanish translation was also available. The consent allowed the researchers to access the child's medical records to specifically obtain the child's height and weight in order to calculate the child's BMI. The child's BMI was calculated by using the BMI formula; weight in pounds divided by the height in inches squared and then the value multiplied by the constant value 703 (U.S. Department of Health and Human Services, 2005).

A questionnaire type survey was distributed to parent volunteers for completion to indicate their own level of physical activity. Parents also indicated demographic data for their child including age and gender.

For purposes of this study, the International Physical Activity Questionnaire (IPAQ, 2004) was selected; English and Spanish versions were available. The short version of the IPAQ consisting of a self-administered format comprised of seven questions relating to participation in physical activity within the previous 7 days was 
used. The established IPAQ scoring protocol was used to analyze and interpret the results.

The ability to communicate effectively in both English and Spanish was vital for the researchers to be able to recruit enough participants for this study. It was also important to gain the trust of the participants, especially from those who could not read, write, or speak English and would require translated materials and translation assistance. Most parents had the opportunity to complete the questionnaire while waiting for their child to be examined. Some parents preferred or needed to complete the survey after their child's appointment time. There was a space reserved on the questionnaire for a staff member or the researchers to enter the child's height and weight from the medical chart. All completed questionnaires and data information were collected before the family left the clinic. No personal identifying information was on the questionnaire surveys and volunteer participants remained anonymous. All completed surveys were immediately collected and placed in a secure file that was accessible only to the researchers.

After the completed questionnaire was submitted, participants received an ageappropriate toy for their child. Participants also had the opportunity to enter their name and phone number on a raffle ticket, place it in a sealed box, and have the chance to win a child's bicycle to be randomly drawn after completion of the study.

\section{RESULTS}

The research questions were answered using statistical analysis; distribution frequencies (Table 1), correlation calculations to determine any relationships between parental activity levels and their child's BMI results, and the standard Pearson Chi- 
Square calculation. The results of the chi-square analysis for the parent level of activity and child's BMI showed no statistically significant relationship between the two variables for this particular population sample of a total number of 52 valid and completed surveys $(N=52)$. The chi-square value was 10.9 For significance at the 0.05 level, the chi-square value must be greater than or equal to 12.6 .

Of the participants, $94 \%$ of the parents were the mothers $(n=49)$ while only $6 \%$ were the fathers $(n=3)$. The numbers of male and female children were almost equal with $52 \%$ of the participants' children being male $(n=27)$ and $48 \%$ being female $(n=25)$. Spanish was the primary language for $86.5 \%$ participants $(n=46)$ while $11.5 \%$ of the participants preferred to complete the English version $(n=6)$. The primary language was determined by which version of the questionnaire the participants decided to complete.

Questionnaires were analyzed using the IPAQ scoring protocol. Each parent was categorized as having either a low, moderate, or high level of physical activity. The results showed that $19 \%$ of the participants had a low level of physical activity $(n=10)$, $29 \%$ had a moderate level $(n=15)$ and $52 \%$ had a high level of physical activity ( $n=27)$ (Table 3). The researchers utilized a statistical consultant to assist with data analysis and interpretation.

After calculating each child's body mass index and graphing each one on the appropriate growth chart, $2 \%$ of the children were considered to be underweight $(n=1)$, $56 \%$ were considered to be normal weight $(n=29), 12 \%$ were at risk for overweight $(n=6)$ and $31 \%$ were considered to be overweight $(n=16)$ (Table 2). Each child's body mass index was categorized using the percentiles provided by the Centers for Disease Control. Based on the appropriate growth chart, the BMI's that were under the $5^{\text {th }}$ percentile are 
considered to be underweight, the BMI's that were between the $5^{\text {th }}$ and $85^{\text {th }}$ percentiles are considered to be at a healthy weight, those that were from the $85^{\text {th }}$ to less than $95^{\text {th }}$ percentile are at risk for overweight, and the BMI's that were equal or greater than the $95^{\text {th }}$ percentile are considered to be overweight (Centers for Disease Control, 2006).

\section{DISCUSSION}

The study results indicated that there was no significant relationship between a parent's activity level and their child's BMI. Nevertheless, childhood obesity is growing more prevalent, especially in the community where the research was conducted.

There were 18 parents with a high level of physical activity whose children had a normal body weight, which is the largest group under the normal weight category in comparison to the normal weight children whose parents either had low or moderate physical activity levels (Table 4). This finding may imply that if the parents have a high physical activity level, then their children may at least have a normal body weight. Conflicting with that finding is the number of overweight children whose parents also had a high level of physical activity. There were 9 overweight children whose parents had a high physical activity level. This group is the largest in the overweight category in comparison to the overweight children whose parents had either low or moderate physical activity levels. This finding does not agree with the assumption that parents with a high physical activity level will have children with normal BMI's.

The children in the study ranged in age from 2- to 16-years-old, with an almost equal number being male and female. The parents whose children were under the age of 
2-years-old had invalid data for the researcher because the BMI can only be calculated for those who are at least 2-years-old.

The majority of the parent participants were mothers. There were 49 mothers and only 3 fathers that participated in completing the questionnaire. In Hispanic families in this community, the mother tends to stay home with the children while the father is working. Obtaining only the mothers' information about physical activity and excluding the fathers' activity level may affect the results. In future studies, both the mothers' and fathers' physical activity level should be obtained to have a more accurate association with the BMI's.

The questionnaire survey for this study may have been limited for this particular setting. The specific tool from IPAQ may not accurately reflect this specific population group. Although the response rate was $100 \%$, some survey results were omitted because the children were too young to have BMI measurements or surveys were not fully completed. The participants may have also been too embarrassed to ask questions about the questionnaire and may not have fully understood the questions. Although the questionnaire was provided in the participants' primary language, some of the questions may have been confusing. For example, the questions ask if the participant takes part in "vigorous" and "moderate" activities. Examples of these types of activities are stated after each question but the participant may have misunderstood the meanings. The questions also ask for specific information regarding how many hours per week one walks. The researchers must rely on the participants' estimates whether or not the estimate is accurate. 
This study was limited to clients utilizing a school-based neighborhood clinic. The clients who use the clinic are typically the under-insured, of lower socioeconomic status and do not reflect the entire school district population. Many of the survey respondents were Hispanic and many were new residents in the United States. Therefore, many of the parent respondents considered themselves as being very active and walked frequently for transportation or may have a job requiring a lot of physical activity, such as farming. Many new U.S. residents can not afford, do not own, or have access to automobiles and must rely more on physical walking for transportation. It would be interesting to see if families that become more acculturated to the American lifestyle if that would have more of an impact on their activity levels and their child's BMI. It would be beneficial to collect more demographic data about the parents, including educational level, occupation, and age thus allowing analysis of additional factors.

\section{IMPLICATIONS FOR SCHOOL NURSING PRACTICE}

The home and school environments have the potential to promote healthy diet practices and regular physical activity. Children are influenced by the parents' diet and activity choices and look to them for guidance and role modeling. Peers and friends at school also influence children's choices.

The National Association of School Nurses (NASN) recognizes the importance of the presence of school nurses in the school setting and takes the position that schools are a natural setting to influence health and well being in students. School nurses have the knowledge and expertise to assess the needs of children who are overweight or at risk of being overweight (NASN, 2002). 
Schools and school-based community clinic settings can promote or utilize existing programs, resources, and tools to develop student and community knowledge, attitudes, and necessary skills for healthy lifestyles. Parents and families can learn a great deal from educational resources to achieve a knowledge base to enhance the family health status. Families can learn that keeping fit and physically active together can help the entire family reduce risks for obesity and obesity related diseases. Promoting physical activity is important because it may help young people to be more involved in physical activity resulting in decreased BMI. Awareness of genetic influences is important in researching the relationship between the parents' and children's weight so that all factors can be considers.

People begin to establish their own health-related behaviors during childhood and adolescence. The school nurse has the opportunity to teach school age students the importance of physical activity and increase their knowledge about its positive health effects. If students gain knowledge about the health consequences that can arise from being obese or overweight, then they may follow the recommendations given to them regarding diet and exercise. This information should be reinforced constantly because as these children get older and into adolescence, physical activity levels tend to decrease.

The school nurse should also assess the needs of students and families to intervene appropriately and focus on prevention. Providing health education in the classroom and implementing BMI assessments are major activities within the school nurse role. The school nurse can send BMI information and standards home to parents after student screenings are performed with recommendations for diet and exercise. The 
school nurse can also refer families to various programs and community activities to increase physical activity.

The school nurse should serve as an advocate in the schools regarding physical activity. The school nurse can present information to the school board, teachers and staff, showing how prevalent obesity is and how serious are the consequences. Physical activity should be increased not only in physical education classes, but extracurricular activities as well. These activities can be provided and promoted to the students and parents so that they can take advantage of those opportunities.

The school nurse is also an educator. The school nurse should educate not only the students and parents, but also the staff members. The school nurse should take responsibility in providing the knowledge needed for everyone to understand the importance of physical activity and the major health problems associated with obesity.

The school nurse can play a significant role in increasing knowledge about physical activity and its benefits as well as information about obesity and its health consequences for students, families, and staff members. The school nurse can also collaborate with the school's nutritional food services to provide healthier food choices for the student. It is the duty of the school nurse to accomplish the goals of advocating for that physical activity be increased and that obesity can be decreased. 


\section{REFERENCES}

California Center for Public Health Advocacy. (2005). The growing epidemic: Child Overweight rates on the rise in California assembly districts. Retrieved November 28,2005 , from http://ww.publichealthadvocacy.org/policy_briefs/overweight_and_unfit.html

Centers for Disease Control and Prevention. (2006). BMI-body mass index: about BMI for children and teens. Retrieved February 28, 2006, from http://www.cdc.gov/nccdphp/dnpa/bmi/childrens_BMI/about_childrens_BMI.htm

Centers for Disease Control and Prevention. (2005). Public health strategies for preventing and controlling overweight and obesity in school and worksite settings. Morbidity and Mortality Weekly Report, 54, 1-12.

Danielzik, S., Langnase, K., Mast, M., Spethmann, C., \& Muller, M. (2002). Impact of parental BMI on the manifestation of the overweight 5-7 year old children. European Journal of Nutrition, 41(3), 132-138.

Fisher, A., Lange, M. A., Young-Cureton, V., \& Canham, D. (2005). The relationship between perceived and ideal body size and body mass index in $3^{\text {rd }}$-grade low socioeconomic Hispanic children. The Journal of School Nursing, 21(6), 224-228. 
Gance-Cleveland, B., \& Bushmiaer, M. (2005). Arkansas school nurses' role in statewide assessment of body mass index to screen for overweight children and adolescents. The Journal of School Nursing, 21(2), 64-69.

Hesketh, K., Waters, E., Green, J., Salmon, L., \& Williams, J. (2005). Healthy eating, activity and obesity prevention: A qualitative study of parents and child perceptions in Australia. Health Promotion International, 20, 19-26.

International Physical Activity Questionnaire (IPAQ). (2004). Retrieved October 12, 2005, from http://www.ipaq.ki.se

Leading Health Indicators. (2000). Healthy People 2010. Retrieved November 16, 2005, from http://www.healthypeople.gov/Document/HTML/uih/uih_4.htm

National Association of School Nurses (NASN). (2002). Position statement: Overweight children and adolescents. Retrieved May 7, 2006, from http://www.nasn.org/positions/overweight.htm

National Center for Health Statistics. (2005). Prevalence of overweight among children and adolescents: United States, 1999-2002. Retrieved November 16, 2005, from http://www.cdc.gov/nchs/Default.htm 
Pangrazi, R., Bieghle, A., Vehige, T., \& Vack, C. (2003). Impact of Promoting Lifestyle Activity for Youth (PLAY) on children's physical activity. Journal of School Health, 73(8), 317-321.

Rich, S., DiMarco, N., Huettig, C., Essery, E., Andersson, E., \& Sanborn, C. (2005). Perceptions of health status and play activities in parents of overweight Hispanic toddlers and preschoolers. Family and Community Health, 28(2), 130-141.

Santa Clara County Public Health department (2003). Santa Clara County's children and youth: Key indicators of well-being. San Jose, CA: Cross Systems Evaluation.

Santa Clara County Public Health Department (2005). Results from the California Healthy Kids Survey: Santa Clara County 2004 Chartbook. San Jose, CA: Author.

School Health Clinics of Santa Clara County. (2005). Retrieved December 5, 2005, from http://www.schoolhealthclinics.org

Social Learning Theory. (2005). Explorations in learning \& instruction: The theory into practice database. Retrieved December 5, 2005, from http://www.tip.psychology.org/bandura.html 
U. S. Department of Health and Human Services. (2000). Healthy People 2010. Washington, DC: U. S. Department of Health and Human Services.

U. S. Department of Health and Human Services. (2005). The Surgeon General's call to action to prevent and decrease overweight and obesity. Retrieved October 23, 2005, from http://www/surgeongeneral.gov/topics/obesity

Welk, G., Wood, K., \& Morss, G. (2003) Parental influences on physical activity in children: An exploration of potential mechanisms. Pediatric Exercise Science, $15,19-33$. 
Table 1. Frequency Distribution - Child's BMI Percentile on Growth Chart $(N=52)$

\begin{tabular}{|c|c|c|c|c|c|}
\hline \multicolumn{6}{|c|}{ BMI PERCENTILE OF CHILD'S BODY MASS INDEX } \\
\hline & & Frequency & Percent & Valid Percent & Cumulative Percent \\
\hline \multirow{26}{*}{ Valid } & 3 & 1 & 1.9 & 1.9 & 1.9 \\
\hline & 5 & 1 & 1.9 & 1.9 & 3.8 \\
\hline & 9 & 1 & 1.9 & 1.9 & 5.8 \\
\hline & 10 & 1 & 1.9 & 1.9 & 7.7 \\
\hline & 13 & 1 & 1.9 & 1.9 & 9.6 \\
\hline & 17 & 1 & 1.9 & 1.9 & 11.5 \\
\hline & 20 & 1 & 1.9 & 1.9 & 13.5 \\
\hline & 25 & 4 & 7.7 & 7.7 & 21.2 \\
\hline & 30 & 1 & 1.9 & 1.9 & 23.1 \\
\hline & 35 & 2 & 3.8 & 3.8 & 26.9 \\
\hline & 40 & 2 & 3.8 & 3.8 & 30.8 \\
\hline & 45 & 1 & 1.9 & 1.9 & 32.7 \\
\hline & 55 & 1 & 1.9 & 1.9 & 34.6 \\
\hline & 60 & 4 & 7.7 & 7.7 & 42.3 \\
\hline & 62 & 2 & 3.8 & 3.8 & 46.2 \\
\hline & 65 & 1 & 1.9 & 1.9 & 48.1 \\
\hline & 70 & 2 & 3.8 & 3.8 & 51.9 \\
\hline & 76 & 1 & 1.9 & 1.9 & 53.8 \\
\hline & 80 & 2 & 3.8 & 3.8 & 57.7 \\
\hline & 85 & 4 & 7.7 & 7.7 & 65.4 \\
\hline & 88 & 1 & 1.9 & 1.9 & 67.3 \\
\hline & 90 & 1 & 1.9 & 1.9 & 69.2 \\
\hline & 95 & 1 & 1.9 & 1.9 & 71.2 \\
\hline & 96 & 3 & 5.8 & 5.8 & 76.9 \\
\hline & 97 & 12 & 23.1 & 23.1 & 100.0 \\
\hline & Total & 52 & 100.0 & 100.0 & \\
\hline
\end{tabular}


Table 2. Frequency Distribution - Weight Status of Children $(N=52)$

\begin{tabular}{|c|c|c|c|c|c|}
\hline \multicolumn{6}{|c|}{ BMI LVL WEIGHT STATUS OF CHILDREN } \\
\hline & & Frequency & Percent & Valid Percent & Cumulative Percent \\
\hline \multirow{5}{*}{ Valid } & 1 UNDERWEIGHT & 1 & 1.9 & 1.9 & 55.8 \\
\hline & 2 NORMAL & 29 & 55.8 & 55.8 & 57.7 \\
\hline & 3 AT RISK & 6 & 11.5 & 11.5 & 69.2 \\
\hline & 4 OVERWEIGHT & 16 & 30.8 & 30.8 & 100.0 \\
\hline & Total & 52 & 100.0 & 100.0 & \\
\hline
\end{tabular}

Table 3. Frequency Distribution - Parent Level of Physical Activity ( $N=52)$

PARENT LEVEL OF PHYSICAL ACTIVITY

\begin{tabular}{|l|r|r|r|r|r|}
\hline & Frequency & Percent & Valid Percent & Cumulative Percent \\
\hline Valid & 10 & 19.2 & 19.2 & 19.2 \\
\hline 2 MODERATE & 15 & 28.8 & 28.8 & 48.1 \\
\hline 3 HIGH & 27 & 51.9 & 51.9 & 100.0 \\
\hline Total & 52 & 100.0 & 100.0 & \\
\hline
\end{tabular}

Table 4. Parent's Activity Level vs. Children's BMI Level $(N=52)$

PARENT LEVEL OF PHYSICAL ACTIVITY * BMI LVL WEIGHT STATUS OF CHILDREN Cross tabulation Count

\begin{tabular}{|c|c|c|c|c|c|c|}
\hline & & \multicolumn{4}{|c|}{ BMI LVL WEIGHT STATUS OF CHILDREN } & \multirow[b]{2}{*}{ Total } \\
\hline & & $\begin{array}{c}1 \\
\text { UNDERWEIGHT }\end{array}$ & $\stackrel{2}{\text { NORMAL }}$ & $\begin{array}{l}\text { 3 AT } \\
\text { RISK }\end{array}$ & OVERWEIGHT & \\
\hline \multirow{3}{*}{$\begin{array}{l}\text { PARENT LEVEL OF } \\
\text { PHYSICAL } \\
\text { ACTIVITY }\end{array}$} & $1 \mathrm{LOW}$ & 0 & 4 & 3 & 3 & 10 \\
\hline & 2 & 1 & 7 & 3 & 4 & 15 \\
\hline & 3 HIGH & 0 & 18 & 0 & 9 & 27 \\
\hline Total & & 1 & 29 & 6 & 16 & 52 \\
\hline
\end{tabular}

